\title{
Depression, Encouragement, Restriction and Nationalization: The Socialist Transformation of Private Publishing Industry in Shanghai, 1949-1956
}

\author{
Ting Zhang \\ School of Marxism, Shanghai University of Political Science and Law, Shanghai, China \\ Email: zhangtinghome@126.com
}

How to cite this paper: Zhang, T. (2020). Depression, Encouragement, Restriction and Nationalization: The Socialist Transformation of Private Publishing Industry in Shanghai, 1949-1956. Open Journal of Social Sciences, 8, 161-181.

https://doi.org/10.4236/jss.2020.86014

Received: May 16, 2020

Accepted: June 8, 2020

Published: June 11, 2020

Copyright $\odot 2020$ by author(s) and Scientific Research Publishing Inc. This work is licensed under the Creative Commons Attribution International License (CC BY 4.0).

http://creativecommons.org/licenses/by/4.0/

\begin{abstract}
This paper investigates the historical path of the disappearance of private publishing industry in Shanghai during 1949-1956. Despite its importance in understanding the historical origins of the control of the Communist Party of China (CPC) over publishing industry, the socialist transformation process of Shanghai's private publishing industry has not been fully studied from a generically historical perspective. Starting from the depressive situations of Shanghai's private publishing industry before the establishment of PRC, this paper explores the supportive and regulative policies of the CPC Shanghai authorities after the founding of People's Republic of China (PRC). It also analyzes the large-scale socialist transformation procedures after the proposal of the General Line of Transition Period. It argues that the transition from supportive policies to restrictive ones was not abrupt but rather gradual and continuous and the frequent adjustments of policies demonstrate an adaptive nature based on the concrete historical situations. It also argues this transformation process led to relevant consequences, including the successful establishment of the state-run publishing industry, the re-distribution of the publishing businesses over the country, the intensification of the tendency of the politicization of the publishing industry and other subtle impacts on the culture, economy, and other aspects of China's society in the next several decades.
\end{abstract}

\section{Keywords}

1949-1956, Publishing Industry, Socialist Transformation, Shanghai, Nationalization 


\section{Introduction}

The publishing industry in China, including the editing, printing, publishing and distribution businesses, not only constitutes an important sector of the Chinese economy, but also plays a vital role in building the "socialist culturally powerful country", promoting the "soft power" of China and consolidating the socialist propaganda system (Fan, 2019; Fang \& Xu, 2005; Yun, 2014). As a result, this industry has been under an effective control of the Communist Party of China (CPC) since the establishment of the People's Republic of China (PRC). The historical origins of the effective control over the publishing industry can be largely traced back to the socialist transformation and nationalization of the private publishing industry in the early years of PRC. Since before the founding of PRC, the city of Shanghai had been playing the dominant role in the publishing industry in China, accounting for over 70\% copies of publications of the national total at the beginning of 1949 (Chen, 1993; Yao, 2004), and by the end of 1955, this number was significantly reduced to lower than $19 \%$ (Chen, 1993). In this sense, the socialist transformation process of private publishing industry in Shanghai is crucial to understanding the historical origins of the CPC's control in the entire country's publishing industry.

The nationalization of Shanghai's private publishing industry was relatively smooth, partly due to the adaptive nature of the CPC's policies in this process (Brown \& Pickowicz, 2010; Chin, 2013; Heilmann \& Perry, 2011), although the complicated interaction between the authorities and national bourgeoisie inevitably led to conflicts and compromises. However, previous studies on the publishing and press industries (e.g., Du, 2014; Zhang, 2010), which mainly paid attention to these conflicts and compromises, did not clearly demonstrate the historical path of this smooth success. This paper seeks to answer why and how the CCP could nationalize Shanghai's private publishing industry in a relatively smooth way in such a short time from a general perspective. Furthermore, during 1949-1952, the CPC implemented supportive policies to encourage the development of Shanghai's private publishing industry, while in 1953, the policies gradually became restrictive and finally made Shanghai's private publishing industry totally disappear (Du, 2014; Zhou, 2006). This paper also aims to understand the reason and motivation behind this transition based on the analysis of policy documents and statistical data. In addition, this paper further argues that the relevant consequences of the socialist transformation of Shanghai's private publishing industry include the successful establishment of the state-run publishing industry, the re-distribution of the publishing businesses over the country, the intensification of the tendency of the politicization of the publishing industry. This transformation has heavily shaped the framework of China's publishing industry and continues to influence the contemporary one.

\section{Depression: Shanghai's Private Publishing Industry before the Establishment of PRC}

The rise and development of private publishing industry in Shanghai was closely 
aligned with the history of the city itself. Since Shanghai was forced to be one of the several Treaty Ports in China in Qing Dynasty, the significant economic growth in this city stimulated it to evolve into a center of culture that attracted intellectuals all over the country, which then gave rise to a prompt birth of private publishing industry. At the early stages (by the end of the nineteenth century), private publishing houses in Shanghai only translated books from the Western into Chinese, and after several decades of development, in the Republican era (1912-1949), they were allowed by the authorities to publish official educational textbooks. For the detailed situation of the publishing capitalism in Shanghai before the War of Resistance against Japan, refer to (Chen, 2004; Reed, 2011). For the history of Shanghai publishing industry during the Japan-occupied era, see (Fu, 2011; Song \& Sun, 2000; Yao, 2004). After the victory of the War of Resistance against Japan, private publishing businesses had experienced a temporary booming. However, due to the unstable political and economic environment during the Civil War, the entire private publishing industry was confronted with a worsening business atmosphere and great depression. When the PRC was established in the year of 1949, they were also unable to get adjusted to the new environment and the recession was still lasting.

\subsection{A Brief History of Private Publishing Industry in Shanghai before 1949}

At the beginning of Shanghai's opening as a treaty port, a number of bookstores publishing Chinese classics like Four Books and Five Classics (sishu wujing) were launched. With the foundation of a translation house attached to the Jiangnan Shipyard (Jiangnan zaochuanchang) in 1867, there were bookstores around the Fuzhou Road and Henan Road which began to publish and print more types of books including classics, histories, biographies and collected series (jing shi zi ji) and books on medicines, divination, astrology (yi bu xing xiang).

This area then gradually became the center of Shanghai's book industry. After Wuxu Reform (wuxu bianfa, 1898) that created a tilde of democratic revolution, the publishing industry further developed in a vigorous way, in which they started to publish social and natural science books to spread Western thoughts and culture. At the same time, the publishing industry had made great progress in the field of education such that many large and small bookstores were focused on trading textbooks and school stationeries. Later, inspired by the Russian Revolution in 1917, the May Fourth Movement (wusi yundong) in 1921 and the foundation of the Soviet Union in 1922, many bookstores in Shanghai, such as Taidong, Beixin, Chuangzaoshe, Xiandai, Chuchao, etc., started to print and publish 'progressive' literature and social science books. However, after the failure of the National Revolution (guomin geming) in 1927 the distribution of progressive books underwent frustration, leading to a short period of recession of the book market. After the outbreak of the War of Resistance against Japan, a great deal of publishing houses moved to the hinterland of China. By 1940, there were only about 120 publishing institutions, 270 printing institutions, and 436 
periodicals in Shanghai (SHCBJ, 1955, B167-1-460-2)1. In general, the publishing industry in Shanghai was still prominent during this time, and as it was put by Pye (1981), by the late 1930s its Commercial Press (Shangwu yinshuguan) was publishing each year as many titles as the entire American publishing industry.

After the victory of the War of Resistance against Japan, Shanghai's private publishing industry began to regain its prosperity as before for a short time. Some of the publishing houses that had moved the hinterland of China then gradually returned to Shanghai; small and medium-sized publishing institutions that had previously stayed in Shanghai also resumed normal businesses; some publishing houses newly established in the hinterland of China, such as Haiyan Bookstore (Haiyan shudian) and Dafu Publishing House (Dafu chubanshe), also moved to Shanghai. Under the inspiring climate of victory, the publishing industry once demonstrated a vigorous rebirth, and the books and periodicals published by the private publishing sector in Shanghai took over almost half of the total publications in China. Yet the good times didn't last long. The domestic situation changed drastically due to the outbreak of the Civil War. Hyperinflation in the financial market in Shanghai led to social chaos, followed by a stricter censorship policy imposed by the Republican government that aimed to stabilize the situation. As a result, Shanghai's private publishing industry significantly shrank with a severe financial and operational crisis. In 1946, there were 258 publishing institutions (including bookstores) in the city, and there were only about 70 major publishing institutions in 1947 (SHCBJ, 1955, B167-1-460-2).

\subsection{The Situation of Private Publishing Industry in Shanghai at the Birth of PRC}

After the takeover of Shanghai by CPC in May 27, 1949, the Shanghai Culture and Education Management Committee of the Shanghai Military Control Commission (SMCC) began its administration on cultural market. In order to stabilize the private publishing business and promote the publishing policies of the new government, two main measures were proposed and implemented, including jieguan (taking over) and tuanjie (unification). For a general history of the takeover of Shanghai, refer to Cochran (2010). The first policy, jieguan, was to receive and manage private publishing institutions which were directly related to the Nationalist (Guomindang, GMD) government in a strict and military way. This policy was implemented according to the requirement in the Interim Regulations on the New Areas' Publishing Undertakings of the CPC Central Committee (Zhonggong zhongyang guanyu xinqu chuban shiye de zhengce de zanxing guiding), which was proposed by CPC Central Committee in 1948. SMCC first took over the publishing organizations of the GMD government and its affiliated institutions, all of whose books, printing factories and other properties were confiscated. These organizations included some large publishing houses like Zhengzhong Book Company (Zhengzhong shuju), China Culture Service Agency (Zhongguo wenhua fuwushe), Independence Press (Duli chubanshe) as ${ }^{1}$ Hereafter, all archivals are cited as follows: creator(s), access number. 
well as medium and small bookstores like Bati Bookstore (Bati shudian), Youth Bookstore (Qingnian shudian) and Bingxue Bookstore (Bingxue shudian), etc. SMCC imposed a military-style management in the publishing houses and thus reserved the property rights of them. Other residual propaganda and publishing institutions of GMD, publishing businesses owned by bureaucratic capitals as well as some publishers that issued porno magazines, were also treated this way.

The other measure, tuanjie, indicated the balancing of state-private relationship and the unity of public and private resources. This measure was a genuine implementation of the United Front (tongyi zhanxian) policy of the CCP for the national bourgeoisies under the regime of New Democracy. In 1949, there were still a number (over 300) of private publishing houses owned by national bourgeoisies, occupying a larger proportion in the whole publication market than the state-owned publishing industry (obtained mainly from the jieguan policy). These publishers could be approximately divided into the following types: large and general publishing houses with a relatively long history, such as the Commercial Press, Zhonghua Book Company (Zhonghua shuju), World Book Company (Shijie shuju), Dadong Book Company (Dadong shuju), Kaiming Bookstore (Kaiming shudian); medium-sized publishers, such as Longmen, Lixin, Beixin, Guangyi, Xinya, etc; and small bookstores including over 70 comic series (paomashu) suppliers, over 60 popular book publishers, over 10 children's book publishers, and more than 20 picture card publishers, as well as over 10 map publishers and 11 religious publishing companies. In the meantime, there were also more than 50 members of the Association of New Publishers (xin chubanye lianying shudian), which had already participated the United Front and operated under the leadership of CPC before the takeover of Shanghai, such as Qunyi, Xinqun, Pingming, Wenhua Shenghuo, Chenguang, Zuojia, Gengyun, Shanghai Publishing House (Shanghai chuban gongsi), Shanghai Magazine Company (Shanghai zazhi gongsi) (SHCBJ, 1955, B167-1-460-2). Their publications were usually more serious and progressive.

Overall, the early takeover and administration of Shanghai's private publishing industry of SMCC was, although complex and tricky, rather smooth. In accordance with the tuanjie policy, some large publishing companies had received substantial aid from the government, began to make self-adjustment and restructuring, and overcome the depression. However, much more smaller publishing companies were unable to adapt to the new environment and kept stuck in the depression. There were mainly three difficulties in front of them. The first was the shrinking of publishing market owing to the decline of textbook sales as a consequence of the change of government. In this situation, many small private publishing companies stopped their publishing businesses and turn around to sell stationeries. The second was the reduction of publishing professionals due to the fact that many professional employees moved out of mainland China and went to Hong Kong, Taiwan and overseas, which made the publishing companies unable to operate normally. The third was the large deficit in the private distribution and printing businesses as a result of the shrinking of publishing 
industry, which further aggravated the depressed situation.

\section{Encouragement: Rehabilitating Shanghai's Private Publishing Industry}

After the takeover of Shanghai, in addition to the straightening out private publishing industry under a growing recession, a more important measure of the CPC was the implementation of supporting and encouraging policy for Shanghai private publishing industry. This policy arose from the complicated historical conditions. Since the publishing industry was regarded as an important field for the propaganda of ideology, it was a critical task to establish effective administration on this industry. However, for a city which occupied half of the country's publishing market, the state-owned publishing industry of the new government, which was only at its infancy, was unable to meet all the demands from such a large market at that time. As estimated by Hu Yuzhi, then Head of the General Administration of Publication (GAP) of the Central Government, the state-owned distribution business could only account for a quarter of the national total and the state-owned printing business was only one-ninth of the private sector ( $\mathrm{Yu}$ an, 1995: p. 259, 264). The integration and transformation of the private publishing industry cannot be achieved as soon as overnight. In addition, as a promise of the New Democracy society and the principle of United Front, the CPC still needed the support of national bourgeoisies in the publishing industry, who were still influential in the city and even in the country, e.g., the president of the Commercial Press, Zhang Yuanji. Therefore, at the same time of the gradual establishment, development and strengthening of the state-owned publishing system, until 1951, CPC continued to support and encourage the private sector of the publishing industry in Shanghai.

\subsection{The "gongsi jiangu" Principle}

The administration of the private publishing industry during late 1949-1950 was carried out under the principle of gongsi jiangu, which meant to take both state-owned and private businesses into consideration. To be more specific, it was not only important to strength the supervision over this culture industry, but also very critical to provide substantial supports to the survival and development of the private sector, in order to achieve the fullest of the interests for both public and private sectors. To promote the understanding and acceptance of the CPC's supporting policy among people who worked in the private publishing industry, in November 1949, the preparing committee of Shanghai Association of Publishing Workers (Shanghaishi chuban gongzuozhe xiehui chouweihui) sent a group ${ }^{2}$ composed of managers and professional workers in the publishing industry to visit north and northeast China, where the supporting policy was first implemented and reached substantial achievements. This visit ${ }^{2}$ It was called Group of Shanghai publishing Industry Visiting North and Northwest China (Shanghaishi chubanye huabei huadong canguantuan). 
provided detailed information and concrete examples about the supporting measures on editing, printing, publishing, paper supply, royalty system and other aspects of the industry. After this visiting group returned to Shanghai on December 14th, 1949, they introduced and conveyed their knowledge, experiences and feelings during this tour through several conferences. This activity demonstrated a successful orientation of new policies for the private publishing industry.

In accordance of the CPC Central Committee's policy of "tongchou jiangu (making overall plans and take all factors into consideration), fengong xiezuo (cooperating closely with an appropriate division of labor), gede qisuo (playing their proper roles)", in September 1950, the GAP held a national publishing meeting to emphasize that the developing direction of the publishing industry was to "serve the people (wei renmin fuwu)", which implied that the private sectors should not only abide the law, but also operate under the leadership of the government and state-owned industry. In the meanwhile, the conference introduced the government's policy to the delegates of publishing industry in Shanghai, resolving their doubts and improving their confidence in overcoming difficulties. Lu Dingyi, then head of the Publicity Department of the CPC Central Committee, also mentioned in his closing remarks of the conference (Lu, 1995):

We shall make it clear to private publishers that, under the Common Program (gongtong gangling), the private publishing businesses always have things to do and they should work hard rather than be permissive... The private publishing businesses should obey the laws of the state. However, within the scope of the laws, they will have the freedom to publish.

From Lu's speech, it can be seen that the CPC held a positive and supportive attitude towards the private publishing industry at the beginning of the foundation of PRC. It was then widely believed that the whole publishing industry necessarily relied on the development of the private sector. Therefore, CPC was more inclined to be "tolerant" towards the private publishing industry, especially after the First National Publishing Meeting, and this attitude was also consistent with the general policies for the whole private capitalism.

With this belief and hope and the supportive policies of the government, private publishing industry in Shanghai gained a significant development in the next three years. In 1950, there were 368 private publishers in Shanghai, with 5388 book titles published, accounting for $44 \%$ of the national total, in which new book titles were 4341 and the total number of book copies was over 92.13 million, accounting for about 30\% of the national total (Song \& Sun, 2000: p. 131). In 1951, although private-private or joint public-private enterprises were established for all of the city's private publishers and the number of publishers was reduced to 353 , the number of book titles surged to 10246, accounting for $55 \%$ of the national total, including 6105 new book titles. The total number of copies of books soared to 248.74 million, accounting for $35 \%$ of the national to- 
tal (Song \& Sun, 2000: p. 132). In August 1952, Shanghai's private publishing companies has reached 391, which was the peak number of the publication history in Shanghai. According to the statistical data of the private publishing industries in 12 major cities from the GAP, private publishing industry in Shanghai ranked in the first place, which took up $33.39 \%$ of the total number of publishers, $64.55 \%$ of the total capital, $36.02 \%$ of the employees, and $60.55 \%$ of the sales figures of the whole country (Yuan, 1998).

\subsection{Shanghai's Private Publishing Industry under the Adjustment of Industrial and Commercial Policies}

A relatively flexible market and supportive policies had greatly helped the recovery of the private publishing industry in Shanghai, which also, to some extent, facilitated the development of the publishing industry in the entire country. However, there were some serious problems occurring under this booming, especially the low quality of many publications, which caused the attention of the Central Government, and as will be seen, partly led to the transition from supportive to restrictive policies over the private publishing sector.

In the first National Publication Administration Meeting held in Beijing from August 27 to September 4, 1951, Lu Dingyi reported the messy situation in the private publishing industry, especially in Shanghai. He made a serious criticism (Ye, 1998):

It must be noted that in the private publishing industry, the situation is quite severe and chaotic... They only focus on producing low-quality publications, copying and reprinting others' works... In popular reading materials, a more chaotic situation can be found. The shoddy comic series (paomashu) is a main type of them. Even in the new comic books, many of them demonstrate severe problems, such as paying a tribute to the GMD, disseminating pornography, advertising distorted stands and other mistakes.

As a consequence, in 1952, the Government Administration Council proclaimed two important acts including Instructions on Strengthening the Leadership and Management of the Private Publishing Industry (Guanyu jiaqiang lingdao he guanli siying chubanye de zhishi) and Interim Regulations on the Administration of the Publishing, Printing and Distribution Industries of Books and Periodicals (Guanli shukan chubanye yinshuaye faxingye zanxing tiaoli). According to these two acts, more than half of the private publishing institutions would be shutdown or entirely cleaned up. However, due to the strength of the state-owned publishing industry was still weak at that time and unable to cover the entire publishing market, this policy was not implemented in a quick move. In November 1952, the Advisory Committee of Improving Publication Works of Shanghai (Shanghai chuban gongzuo gaijin fudao weiyuanhui) was established, which accelerated the rectification work of the city's publishing industry. According to the provisions of the GAP, the Shanghai authority adopted a series of measures including merging and reorganization, joint state-private ownership, 
advising to suspend business and self-elimination, etc., covering over 400 small private publishing companies. Furthermore, the Shanghai authority strengthened the supervision on the editing of publications, with several measures such as rejecting the applications of setting up publishing houses without editorial departments, establishing the central position and specialized duty of editing works in the publishing industry, constructing the editorial responsibility system and the three-trial system, in order to ensure the quality of publications. At the same time, the number of Shanghai's state-owned and joint state-private publishing institutions further increased. According to data from Colloquium for Registering and Tackling with Problems for Publishing, Printing and Distribution industries in Shanghai (Shanghai shukan chubanye yinshuaye faxingye dengji chuli wenti zuotanhui) held in May 13, 1953, the number of publishing institutions that were allowed to operate was 324, of which 8 are state-owned, 4 are joint state-private enterprises and 312 are private-owned (SHRZWJW, 1953: B34-1-110).

\section{Restriction and Nationalization: Shanghai's Private Publishing Industry under the General Line of Transition Period}

Since the beginning of 1952, along with the substantial progress in the Three Anti Campaign (san fan yundong) in major cities in the country to combat "corruption, waste, and bureaucratism" (tanwu, langfei, guanliaozhuyi) of the cadres, the Five Anti Campaign ( wu fan yundong) was launched, which aimed to attack illegal activities, including "bribery, tax evasion, stealing state assets, cheating on government contracts, theft of economic intelligence" (xinghui, toushui loushui, daopian guojia cai chan, tougong jianliao, daoqie guojia jingji qingbao) of the national bourgeoisie. For an introduction to the two campaigns, refer to (Lin, 2006; Walder, 2015). Although the authorities declared that there was no change in the policies for the private sectors of the economy as well as the national bourgeoisie in the campaigns, it was regarded as a "very strong socialist step" towards the transformation of the private sector operated by the national bourgeoisie (Yu, 2005).

In December 1953, the CPC Central Committee proposed the General line for the Transition Period (guodu shiqi zongluxian), which implied that the private publishing industry, with no exception, was put in the list of socialist transformation. According to the Central Government's policy, the East China Press and Publication Bureau (Huadong xinwen chuban ju) issued the Plan to Rectify Shanghai's Private Publishing Industry (Zhengdun Shanghai siying chubanye fangan), which planned to basically incorporate Shanghai's private businesses into the national publishing system around 1955.

\subsection{Constantly Restricting Shanghai's Private Publishing Industry}

Although in the early days of PRC, the public and private publishing industries 
had worked together and created a prosperous market. However, with the continuous consolidation of nationalization procedures, especially the specialization of publishing industry and the establishment of state-owned distribution channels dominated by Xinhua Bookstore, the government constantly squeezed the space of survival and development of private publishing businesses. In Shanghai, this squeezing was more visible due to its large-scale private sector.

The nationalization measures were mainly implemented in the publishing and distribution parts of the industry. For the publishing process, the authorities attempted to strictly control the publishing rights of private publishers. Firstly, the private publishing industry was not permitted to publish any kinds of political publications, ranging from party documents and party leaders' speeches to government's decrees and even common political reading materials. Secondly, their rights to edit and publish textbooks, which essentially occupied a large proportion of publications and were once one of most profitable businesses of the private publishing sector, were abolished. On July 3, 1954, the Ministry of Education and the General Administration of Press and Publication jointly promulgated the Provisions on the Textbooks and References for Secondary Schools, Primary Schools, Normal Schools, Kindergartens and Textbooks for Workers, Peasants, Soldiers and Women (Guanyu chuban zhongxue, xiaoxue, shifan, youeryuan keben, jiaocai, jiaoxue cankaoshu he gongnongbing funv keben, jiaocai de guiding), which formally prohibited private publishers from publishing almost all education related books and made it become the state's monopoly (Yuan, 1999). For example, to the Commercial Press, which was one of the largest and most representative private publishing houses, this measure suddenly resulted in a business crisis due to its heavy dependence on textbook publications. Thirdly, the state control over contribution sources for publications were further strengthened. Based on the considerations of culture GAP prohibited the employees of the government and its affiliated institutions from contributing works to private publishers. In November 1952, Chen Kehan, the Secretary of the Leading Party Members' Group of the GAP, pointed out in a report to the CPC Central Committee (Chen, 1998).

We also request the Central Committee to inform the local party organizations to strengthen the leadership of the publishing works, to promote their local departments to help the publishing works, and in particular, to encourage and urge those who have writing and translation experiences to dive into the writing, translation, review and revision works, and to require that the works written by party members should be first published by state-owned publishing houses, and their works can be published by private companies only when state-owned publishing houses cannot publish them. In this way, we can make the publication industry become an undertaking of the entire party.

This policy largely reduced the contribution sources and made the situation of private publishers more difficult because there were fewer intellectuals contributing their works for publication as a result of the previous Thought Reform Movement (sixiang gaizao yundong). In addition, it also became more difficult 
for private publishing companies to get loans from banks, which were strictly controlled by the authority.

For the distribution business, the distribution channels of private publishing industry were also strictly controlled. The GAP had been dedicated to building the Xinhua Bookstore system over the country, in order to make it the main channel of the book distribution. By the end of 1951, Xinhua Bookstore system had 1086 bookstores in various cities and counties across the country, and rapidly developed into the nationwide leading and well-organized distribution network. After the First National Publishing Meeting, the GAP promoted the setup of the China Book Distribution Company, which was jointly operated by the state-owned and private distribution companies (composed of Sanlian Bookstore, Lianhe Bookstore and the Commercial Press, the China Book Company and Kaiming Bookstore, all in Shanghai). This company also played an important role in the nationwide distribution network. In 1954, this company was merged into the Xinhua Bookstore with the private stock shares drawn back, which then gained the monopoly of the distribution network throughout the country, while private book distribution industry rapidly shrank and then disappeared. Statistics showed that in 1954 the Xinhua Bookstore system occupied $98 \%$ purchasing value of the books published this year, of which only $8 \%$ was wholesale sold to private bookstores (Fan, 2019; Fang \& Xu, 2005). This situation could be seen more clearly in Shanghai. At the beginning of 1949 there were only two shops of Xinhua Bookstores, while in 1954 the company had 26 bookshops and 26 bookstalls (Huadong xinhua shudian jianshi bianxiezu, 1998), and in 1958 the total number of book distribution outlets reached 1093, taking up more than a quarter of the total 3876 outlets all over the country (Ha, 2007).

In addition, Shanghai government imposed a more stringent control over the license of the publishing industry. As a result, some private publishing companies that did not meet the requirements of the government could not obtain the licenses of publishing, printing, and distribution, which implied that they had to close their businesses. Some of them tried to write a letter to the central government to argue (Yao, 2004):

... the East China Press and Publication Bureau resolutely did not issue the Shanghai majority of private publishing license, the business cannot continue ... such that thousands of workers and their families would possibly die, leading to severe social problems. It is a also behavior that will definitely undermine Article 5 of the Common Program.

And they also requested the GAP "to quickly notice East China Press and Publication Office in telegraph ... to relax the requirements of issuing the license" (Yao, 2004). However, their request was not supported by the Central Government. By the end of 1953, the number of private publishing houses had decreased from 337 to 252. By the end of June 1953, the number of printing companies had decreased from 341 to 127; by the end of July 1953, the number of distribution companies had decreased from 404 to 201 (Song \& Sun, 2000: p. 134). It can be seen that at this time, Shanghai's private publishing industry was 
in an extremely difficult situation, deprived of means to compete and grow.

\subsection{Gradually Promoting the Socialist Transformation of Shanghai's Private Publishing Industry}

Along with the squeezing the space of survival and development of Shanghai's private publishing businesses, after 1953 the East China Press and Publications Bureau, on the basis of the Report on the Publishing Work and Future Directions and Tasks of 1953 (Guanyu 1953 nian chuban gongzuo he jinhou fangzhen renwu de baogao) put forward by the GAP, started a systematic socialist transformation for them.

Firstly, for large private publishing enterprises, the authority started to establish joint state-private enterprises, which was an important step towards the socialist transformation of private publishing industry and the establishment of the state-run publishing system. On December 4, 1953, the Press and Publication Bureau of the East China Military and Political Committee sent a letter to the Publicity Department of the CPC Shanghai Municipal Committee (HDJZWXWCBJ, 1953: A22-2-176):

In accordance with the instructions of the Publicity Department of the CPC Central Committee and the GAP, it is decided to reorganize the Commercial Press and the Zhonghua Book Company into joint state-private enterprises, which will be led and managed by the government with more cadres sent by necessity, and will also be invested by the government in order to consolidate the leadership and publish books according to the realistic demand of the country. To carry out the concrete organization work in Shanghai, it is decided to establish a working group. The working group's mandate is to promote the Commercial Press and the Zhonghua Book Company to enter the joint state-private enterprises totally and respectively. In other words, it is aimed to assist in the cleansing process of assets, reorganize the welfare systems, assist in handling with overstaffing and allocating some necessary cadres, and urge the general management of the two companies to move to Beijing.

At the end of January 1954, the Minutes of Talks on the Implementation of the Comprehensive joint state-private ownership Reorganization for Higher Education Press by the Commercial Press (guanyu Shangwu Yinshuguan quanmian shixing gongsiheying gaizu wei Gaodeng Jiaoyu Chubanshe de huitan jiyao) and the Minutes of Talks on the Implementation of the Comprehensive joint state-private ownership Reorganized into Financial and Economic Publishers by Zhonghua Book Company (Guanyu Zhonghua Shuju shixing quanmian gongsiheying gaizu wei Caizheng Jingji Chubanshe de huitan jiyao) were issued, which then became the guidance documents for the implementation of joint state-private enterprises of the private publishing industry. According to these guidelines and instructions, under the leadership of the CPC East China Bureau and the Shanghai Municipal Committees as well as the GAP, relevant CPC district committees, trade unions, industry bureaus, trade and industry Bureaus, Bank of Communications worked closely to assist the two companies to 
be reorganized into joint state-private enterprises, and successfully completed this transformation in the middle of April, 1954. The joint state-private ownership of these two companies was one of the most important events in the socialist transformation of Shanghai's private publishing industry.

On the other hand, small and medium-sized private publishing companies, most of which did not have editorial departments and made a living by clipping and copying existing publications, usually did not meet the standards set by the Provisional Regulations on the Management of Books and Periodicals Publishing, Printing and Distribution Industries (guanli shukan chubanye yinshuaye faxingye zanxing tiaoli) promulgated by the Central Government in August 1952. For these companies, the authorities attempted to persuade them to change or terminate their businesses. By the end of 1953, the number of these speculative publishing houses was reduced by 77 in Shanghai ${ }^{3}$, with 252 publishers in the private sector left. In 1954, the GAP further made it clear that "for private speculation publishers, it is required to actively and steadily rectify them, and in 1954 more than 100 publishers that demonstrated severe speculation problems should be eliminated." (GAP, 1954) Under the guidance of these ideas, East China Press and Publication Bureau, in the first quarter of 1954, handled 30 private publishing houses, and in the second quarter, 20 to 25 private speculative publishers were processed. In the third quarter, 38 private publishers were closed or changed their business to only printing or distribution. In the fourth quarter, it was planned to process 63 private publishing houses (HDXZWXWCBJ, 1954: B34-2-265). And by the end of 1955, there were 23 publishers that had made their own decisions to shut down businesses, 121 publishing companies that ceased their businesses after the government's persuasion, and 21 publishers that were forced to a shutdown (SHRWCBGLC, 1956: B3-2-91). And from December 1955 to January 20, 1956, the Shanghai Municipal Press and Publication Bureau approved the joint state-private enterprises of 41 private publishers and one magazine company. The final phase of socialist transformation was the accomplishment of joint state-private enterprises in the entire publishing industry. On November 24, 1955, in the 7th Plenary Session of the Seventh CPC Central Committee, the Resolution on the Socialist Transformation of Capitalist Industries and Commences of the CPC Central Committee (Draft) (Zhongyang guanyu zibenzhuyi gongshangye gaizao wenti de jueyi (caoan)) was approved, which was a systematic plan for the socialist transformation and would soon lead to the upcoming high tide of this movement. Following the spirit of the CPC Central Committee, by the end of December 1955, Shanghai government promulgated the Scheme for the Establishment of joint state-private enterprises of the entire Shanghai Private Book Distribution Industry by Batches (Shanghaishi siying tushu faxingye shixing fenpi quanye gongsi heying de fangan), leading to an accelerated transformation of the publishing industries. Before this scheme, on December 6, 1955, the Preparing Committee of the Shanghai Book Industry ${ }^{3}$ Since there were eight new publishers established as a result of reorganization and merging in this year, the actual number of reduction was 69. 
Association already submitted a joint letter from 42 book dealers and consignment shops to the Shanghai Federation of Industry and Commerce, Shanghai Publishing Industry Administration, and Shanghai Branch of Xinhua Bookstore, which requested to establish an all-industry joint state-private ownership (SHSYTYGH, 1956: B167-1-81).

By the end of 1955, the socialist transformation of the private publishing industry in Shanghai was basically completed, and in the spring of 1956, all private publishing, printing and distribution industries were operated under the framework the national publishing system in the form of joint state-private enterprises. As a result of socialist transformation, the publication and distribution of books in Shanghai shrank rapidly. In the year 1955, there were 5711 kinds of books published in the city, in which 2581 were newly published, accounting for only $27 \%$ and $19 \%$ of those of the entire country (Chen, 1993). Since then, the market share of Shanghai's book publishing industry in the country continued to decline, losing its once advantageous position in the market, which was replaced by that of Beijing.

\section{Discussion}

In the 1950s, the private publishing industry had encountered a variety of up and downs with cooperations and competitions with the public sector. There was no doubt that the winner of the competition would be the public sector because they had the state power behind. In 1956, the socialist transformation of Shanghai's private publishing industry was finally completed, and the publishing industry in Shanghai entered a new and different period of development. It would be instructive to examine this history on its gains and losses in the game as well as the historical impact.

During 1949-1952, the CPC implemented supportive policies to encourage the development of Shanghai's private publishing industry, while in 1953, the policies became restrictive and finally made Shanghai's private publishing industry totally disappear. Here I argue that the transition from supportive policies to restrictive ones was not abrupt but rather gradual and continuous, and the frequent adjustments of policies demonstrated an adaptive nature based on the concrete historical situations. The reason and motivation behind this transition could be understood in a variety of aspects.

Firstly, the nationalization of the private publishing industry was not only a pursuit of the socialism, but also pivot to the propaganda and ideological indoctrination. As Antonio Gramsci argued in the concept of cultural hegemony (Gramsci et al., 1971), an effective ruling does not only come from the materials of production, but also should be based on the ideological and cultural dominance over the people through the media including newspapers, periodicals and books. In this sense, the control of the private publishing industry was critical to the social stability in this newly established regime. Early in the Yan'an days (1937-1947), the CPC already had a well-organized propaganda network. In 
1948, before the founding of PRC, Zhou Enlai instructed to the Head of Publicity Department of the CPC Central Committee: "the publishing undertakings need to be united and centralized, but on the basis of decentralized operations and under favorable and possible conditions, it must be planned and stepped towards unified centralization.” (Ma \& Su, 1999). In the Common Program promulgated in September 1949, it was stated that: “developing the people's publishing undertakings and especially paying attention to publishing instructive and popular books and newspapers for the people". On the "people's publishing undertakings", Hu Yuzhi further expatiated (Yuan, 1995: p. 257):

People's publishing undertakings should refer to the state-run publishing undertakings. In a country under the people's democratic dictatorship (renmin minzhu zhuanzheng), publishing business is a tool for this dictatorship, the leadership of which should be in the hands of the state-run publishing industry under the administration of the people's regime.

To achieve the goal of people's publishing undertakings, the GAP organized the First National Publishing Conference from September 15 to 25, 1950, which then decided to deploy a nationwide adjustment of the state-private relationships in the publishing industry. In the process of adjustment, the GAP insisted that "all professional publishing institutions should accept the leadership of relevant government departments and people's organizations," and it was thus natural for the government to directly use the administrative power to influence the development of the publishing and distribution businesses, making state-owned enterprises grasp almost all publishing and distribution resources and markets.

Secondly, despite it was economically useful, the private publishing industry did not meet the political and cultural needs of the CPC, and this inability was rooted in its historical origins as well as the private ownership of this industry. As analyzed by Hu Yuzhi in October 1949 (Yuan, 1995), the private publishing industry was somewhat "laggard": it had a close relationship with "imperialist" countries as well as GMD's bureaucratic capitalism and heavily depended on them; the organization and management of bookstores and other distribution companies was strongly feudal, operating in a way much like gangsters; it was also controlled by monopoly capitals represented by four to five large bookstores. He further pointed out that the characteristics indicated the semi-feudal and semi-colonial nature of the private publishing industry, which implied a restriction and even expropriation policy for it was in the blueprint of the people's publishing undertakings. However, since at the beginning of the PRC the state-owned publishing industry of the new government was only at its infancy and unable to meet all the demands from such a large market at that time, the CPC was more inclined to be "tolerant" towards the private publishing industry and implemented supportive and encouraging policy. In 1951, under these policies, the private publishing industry in Shanghai flourished with over 100 newly established private publishers, resulting in a disordered market full of opportunistic and low-quality publications, some of which demonstrated severe political and ideological problems (Chen, 1998). This situation raised the concerns of the 
GAP, which then soon adjusted the policy gradually by imposing more restrictions such as a more rigorous registration system, planned regimentation and stricter quality control.

Thirdly, although the private publishing industry seemed to be flourishing even after the GAP implemented an adjustment policy in 1951 and reached its peak in 1952 (Yuan, 1998), it was very weak and became more and more dependent of the state-owned publishing industry, which almost fully controlled the distribution system through the Xinhua Bookstore system. Moreover, without the rights to publishing political publications and textbooks, losing a great deal of contributing sources, difficult to get loans from the state-owned banks, private publishing companies could not compete with large, state-owned enterprises in the market. In this sense, the final nationalization of the private publishing industry which gradually began in 1953 was a natural choice, which was also manifestation of the adaptive nature of the CPC's policies. This gradual process also illustrated that the socialist transformation, although the interactions among the government, public and private sectors of the publishing industry were undoubtedly complicated, to achieve nationalization was basically smooth (Chin, 2013).

I also argue that the socialist transformation of Shanghai's private publishing industry led to several important consequences. Firstly, this transformation critically established the state-run publishing system. After the socialist transformation, Shanghai's private publishing industry, in essence, was completely under the control of the state-run publishing system. Any publication must be distributed through Xinhua Bookstore or other distributors under its management. Moreover, the strict registration and approval system added another control of their living space. In this way, the private publishing companies had no choices but to depend on the state-run industry. The state-run publishing industry developed rapidly, occupying an absolute advantage in the industry, thereby laying the foundation for the development of the publishing industry in PRC.

The second consequence is the re-distribution of the publishing businesses over the country and the localization of Shanghai's publishing industry. Early in 1950, the CPC began to guide and arrange some Shanghai publishing enterprises to move north and the hinterlands, in order to develop the publishing industry in these provinces. And this arrangement was also an opportunity for some private enterprises to obtain more space of development based on an economic consideration. Notably, during 1951-1954, several large and important publishing companies in Shanghai, including the World Affairs Press (Shijie zhishi chubanshe), Kaiming Bookstore, the Commercial Press, the Zhonghua Book Company, mainly moved to Beijing with only offices left in Shanghai. At the same time, many printing companies, like Huadong Arts Printing Company (Huadong meishu yinshuachang), Guoguang Printing Company (Guoguang yinshuachang), Huawen Printing Company (Huawen yinshuachang), also migrated to other provinces including Sichuan, Shaanxi, Hubei, Henan, Jiangxi, etc. (Zhou, 2006). In this sense, although the advantageous position of Shang- 
hai's publishing industry was significantly weakened, its socialist transformation made a great contribution to the "people's publishing undertakings" in other places in China and played an important role in training publishing experts all over the country, like Shanghai's contribution to other industries in China. As it was put by Lucian W. Pye (Pye, 1981):

The city has persisted in being the principal source of funds for that same central government. It has also been the main source of technical skills and administrative talents for China's industrial development ... since 1949 at least one million skilled workers have been sent out from Shanghai.

The third consequence is that the tendency of the politicization of the publishing industry was intensified. Based on its tradition and the needs of China's cultural construction as well as thoughts reform, the CPC gave a high priority for the publishing works. As it was put by Hu Qiaomu, then Head of the General Administration on Press and a deputy head of the Publicity Department of the CPC Central Committee: "in the front line of thoughts and culture, the most important weapon is books, and publishing." (Hu, 1996). Under the guidance of this spirit, the state-owned publishing system not only controls the economic development of private publishing industry, but also was able to influence the contents of publications. As a result, the political character of various publications became prominent, while the commercial character and cultural diversity were significantly suppressed.

Besides these direct consequences, the socialist transformation of private publishing industry in Shanghai in fact had more subtle impacts on the culture, economy, and other aspects of China's society in the next several decades and continue to show influences nowadays.

\section{Conclusion}

In summary, this paper investigates the supportive and regulative policies of the CPC Shanghai authorities after the founding of People's Republic of China (PRC). The large-scale socialist transformation procedures after the proposal of the General Line of Transition Period are further analyzed. Based on statistical data and policy documents, I argue that the transition from supportive policies to restrictive ones was not abrupt but rather gradual and continuous. In fact, the frequent adjustments of policies demonstrated an adaptive nature in accordance with the concrete historical situations. I also argue that this transformation process led to important consequences, including the successful establishment of the state-run publishing industry, the re-distribution of the publishing businesses over the country, the intensification of the tendency of the politicization of the publishing industry and other subtle impacts on the culture, economy, and other aspects of China's society in the next several decades.

Since the socialist reform in the 1970s, private publishing industry, after its disappearance of nearly 30 years, has gradually emerged and grown rapidly after 2000s, with a variety of printing, publishing and distributing companies as well 
as digital publishing institutions. By now, private publishing companies did not obtain the independent publishing rights, although they can already independently edit and distribute publications. In this situation, they could only buy publishing rights from state-owned companies. How to balance the front line of cultural diversity, political propaganda and economic development? How to effectively supervise private publishing industry and guide it to develop healthily? These all would be very important problems that need further investigation, and the experiences gained during the transition period may provide valuable guidance.

\section{Acknowledgements}

The author gratefully acknowledges the support of Shanghai Municipal Philosophy and Social Science Fund (2017EDS001).

\section{Conflicts of Interest}

The author declares no conflicts of interest regarding the publication of this paper.

\section{References}

[GAP] General Administration of Publication of the Central Government (1954). Zhongyang Renmin Zhengfu Chuban Zongshu 1954 nian chuban sheye jihua (Publication work plan in 1954 of the General Administration of Publication of the Central Government). In L. Yuan (Ed.), Zhonghua renmin gongheguo chuban shiliao (1954) (Publication History Materials of the People's Republic of China (1954)) (p. 14). Beijing: Zhongguo Shuji Chubanshe.

[HDJZWXWCBJ] Huadong junzheng weiyuanhui xinwen chuban ju (Press and Publication Bureau of the East China Military and Political Committee) (1953). Huadong junzheng weiyuanhui xinwen chuban ju zhihan zhonggong shanghai shiwei xuanchuanbu (Letter from Press and Publication Bureau of the East China Military and Political Committee to the Publicity Department of the CPC Shanghai Municipal Committee). Shanghai Municipal Archives A22-2-176.

[HDXZWXWCBJ] Huadong Xingzheng Weiyuanhui Xinwen Chuban Ju 1954 nian gongzuo jihua yaodian (Key Points of the 1954 Work Plan of the East China Administration Committee Press and Publication Bureau) (1954). Guanyu Shanghai shukan chubanye yinshuaye faxingye dengji chuli wenti zuotanhui (On the Colloquium for Registering and Tackling with Problems for Publishing, Print and Distribution Industries in Shanghai). Shanghai Municipal Archives B34-2-265.

[SHCBJ] Shanghaishi Chubanju (Shanghai Municipal Bureau of Publication) (1955). Shanghai jiefanghou de chuban gongzuo he zibenzhuyi chubanye de shehuizhuyi gaizao qingkuang (Situations of Publishing Works and the Socialist Transformation of Capitalist Publishing Industry after Shanghai's Liberation). Shanghai Municipal Archives B167-1-460-2.

[SHRWCBGLC] Shanghaishi Renmin Weiyuanhui Chuban Shiye Guanlichu (Publication Work Administration Office of Shanghai Municipal People's Congress) (1956). Shanghaishi Renmin Weiyuanhui Chuban Shiye Guanlichu han (Letter of Publication Work Administration Office of Shanghai Municipal People's Congress). Shanghai $\mathrm{Mu}$ nicipal Archives B3-2-91. 
[SHRZWJW] Shanghaishi renmin zhengfu wenhua jiaoyu weiyuanhui (Culture and Education Management Committee of Shanghai Municipal People's Government) (1953). Guanyu Shanghai shukan chubanye yinshuaye faxingye dengji chuli wenti zuotanhui (On the Colloquium for Registering and Tackling with Problems for Publishing, Print and Distribution Industries in Shanghai). Shanghai Municipal Archives B34-1-110.

[SHSYTYGH] Shanghaishi Shuye Tongye Gonghui Choubeihui (The Preparing Committee of the Shanghai Book Industry Association) (1956). 1955 nian 12 yue 6 ri Shanghaishi Shuye Tongye Gonghui Choubeihui (han) (Letter of the Preparing Committee of the Shanghai Book Industry Association on December 6, 1955). Shanghai Municipal Archives B167-1-81.

Brown, J., \& Pickowicz, P. G. (Eds.) (2010). Dilemmas of Victory: The Early Years of the People's Republic of China. Cambridge, MA: Harvard University Press.

Chen, C. W. (2004). Jindai Shanghai Chubanye yu Dushi Shequ de Hudong (The Interaction between Publication Industry and Community in Modern Shanghai). Xueshu Yuekan (Academic Monthly), 7, 60-66.

Chen, K. H. (1998). Chuban zongshu dangzu shuji Chen Kehan guanyu zhaokai dierjie quanguo chuban faxing huiyi de qingkuang xiang wenwei dangzi bing bao dangzhongyang de baogao (Report to Leading Party Member's Group of Culture and Education Committee of Government Administration Council and the CPC Central Committee of the Secretary of the Leading Party Members' Group of the General Administration of Publication Chen Kehan on calling the second National Publication Administration Meeting). In L. Yuan (Ed.), Zhonghua renmin gongheguo chuban shiliao (1952) (Publication History Materials of the People's Republic of China (1952)) (p. 313). Beijing: Zhongguo Shuji Chubanshe.

Chen, X. (1993). Dangdai zhongguo de shanghai (xia) (Shanghai of Modern China (Vol. 2)). Shanghai: Dangdai Zhongguo Chubanshe.

Chin, S. J. (2013). The Historical Origins of the Nationalization of the Newspaper Industry in Modern China: A Case Study of the Shanghai Newspaper Industry, 1937-1953. China Review, 13, 1-34. http://www.jstor.org/stable/23611063

Cochran, S. (2010). "Cleanup": The New Order in Shanghai. In J. Brown, \& P. G. Pickowicz (Eds.), Dilemmas of Victory: The Early Years of the People's Republic of China (pp. 22-58). Cambridge, MA: Harvard University Press.

Du, Y. (2014). Shanghaiing the Press Gang: The Maoist Regimentation of the Shanghai Popular Publishing Industry in the Early PRC (1949-1956). Modern Chinese Literature and Culture, 26, 89-141. http://www.jstor.org/stable/43492545

Fan, J. (2019). The Publishing Industry in New China: Eventful 7 Decades. Publishing Research Quarterly, 35, 629-647. https://doi.org/10.1007/s12109-019-09694-0

Fang, Q., \& Xu, L. F. (2005). A Brief History of Non-State-Owned Book Businesses in China. Publishing Research Quarterly, 21, 56-64.

https://doi.org/10.1007/s12109-005-0033-6

Fu, J. (2011). Lunxian Shiqi Shanghai de Chubanye yu Lishi Yanjiu (Publishing Industry and History Research from 1937 to 1945 in Occupied Shanghai). Shoudu Shifan Daxue Xuebao Shehui Kexue Ban (Journal of Capital Normal University, Social Sciences Edition), No. 3, 35-42.

Gramsci, A., Hoare, Q. et al. (1971). Selections from the Prison Notebooks. London: Lawrence and Wishart.

Ha, J. R. (2007). Xinhua shudian qishi jishu (1937-2006) (A Seven-Decade History of Xinhua Bookstores (1937-2006)). Shanghai: Shanghai Renmin Chubanshe. 
Heilmann, S., \& Perry, E. J. (Eds.) (2011). Mao’s Invisible Hand: The Political Foundations of Adaptive Governance in China. Cambridge, MA: Harvard University Asia Center. https://doi.org/10.2307/j.ctt1sq5tc6

Hu, Q. M. (1996). Gaijin chuban gongzuo de jige wenti (zai diyijie quanguo chuban xingzheng huiyi shang de baogao) (Several Issues on Improving the Work on Publishing (Report in the First National Publication Administration Meeting)). In L. Yuan (Ed.), Zhonghua renmin gongheguo chuban shiliao (1950) (Publication History Materials of the People's Republic of China (1950)) (p. 245). Beijing: Zhongguo Shuji Chubanshe.

Huadong xinhua shudian jianshi bianxiezu (1998). Huadong xinhua shudian jianshi (1949-1954) (A Concise History of East China Xinhua Bookstores (1949-1954)). Shanghai: Wenhui Chubanshe.

Lin, C. (2006). The Transformation of Chinese Socialism. Durham, NC: Duke University Press.

Lu, D. Y. (1995). Quanguo Xinhua Shudian chuban gongzuo huiyi shang de bimenci (Closing Remarks in the National Xinhua Bookstore Publishing Conference). In L. Yuan (Ed.), Zhonghua renmin gongheguo chuban shiliao (1949) (Publication History Materials of the People's Republic of China (1949)) (pp. 444-445). Beijing: Zhongguo Shuji Chubanshe.

Ma, Z. Y., \& Su, K. C. (1999). Huiyi chuban jia huang luofeng (In Memory of Huang Luofeng, the Publisher). In Y. L. Song, X. S. Yuan, \& X. M. Liu (Eds.), Zhongguo dangdai chuban shiliao: di wu juan (China's Contemporary Publication History Materials: Vol. 5) (p. 201). Zhengzhou: Daxiang Chubanshe.

Pye, L. W. (1981). Foreword. In C. Howe (Ed.), Shanghai: Revolution and Development in an Asian Metropolis (pp. xi-xvi). Cambridge: University Press Cambridge. https://doi.org/10.1017/CBO9780511560040.002

Reed, C. A. (2011). Gutenberg in Shanghai: Chinese Print Capitalism, 1876-1937. Vancouver: UBC Press.

Song, Y. F., \& Sun, X. (2000). Shanghai chuban zhi (Shanghai Publication History). Shanghai: Shanghai shehui kexueyuan chubanshe (Press of Shanghai Academy of Social Sciences).

Walder, A. G. (2015). China under Mao: A Revolution Derailed. Cambridge, MA: Harvard University Press. https://doi.org/10.4159/9780674286689

Yao, F. S. (2004). Zhongguo bianji shi (xiudingben) (Chinese History of Editing (revised version)). Shanghai: Fudan University Press.

Ye, S. T. (1998). Wei tigao chubanwu de zhiliang er fendou (Diyijie quanguo chuban xingzheng huiyi shang de baogao) (Work Hard for Improving the Quality of Publications (Report on the First National Publication Administration Meeting)). In L. Yuan (Ed.), Zhonghua renmin gongheguo chuban shiliao (1951) (Publication History Materials of the People's Republic of China (1951)) (p. 234). Beijing: Zhongguo Shuji Chubanshe.

Yu, G. Y. (2005). "Xin minzhu zhuyi shehui lun" de lishi mingyun-dushi biji (The Historic Destiny of "On New Democratic Society"-Notes on Reading History. Wuhan: Changjiang Wenyi Chubanshe.

Yuan, L. (Ed.) (1995). Zhonghua renmin gongheguo chuban shiliao (1949) (Publication History Materials of the People's Republic of China (1949)). Beijing: Zhongguo Shuji Chubanshe.

Yuan, L. (Ed.) (1998). Zhonghua renmin gongheguo chuban shiliao (1952) (Publication 
History Materials of the People's Republic of China (1952)). Beijing: Zhongguo Shuji Chubanshe.

Yuan, L. (Ed.) (1999). Zhonghua renmin gongheguo chuban shiliao (1954) (Publication History Materials of the People's Republic of China (1954)). Beijing: Zhongguo Shuji Chubanshe.

Yun, Q. (2014). From Communization to Commercialization: A Brief History of China's Publishing, 1949-1992. Journal of Scholarly Publishing, 45, 142-171. https://doi.org/10.3138/jsp.45.2.003

Zhang, J. S. (2010). Thought Reform and Press Nationalization in Shanghai: The Wenhui Newspaper in the Early 1950s. Twentieth-Century China, 35, 52-80. https://doi.org/10.1353/tcc. 0.0030

Zhou, W. (2006). Cong quanguo dao difanghua: 1945 zhi 1956 nian Shanghai chubanye de bianqian (From National Scale to Local Scale-On the Change of Publishing Business between 1945 and 1956). Shi Lin (Historical Review), No. 6, 72-95. 